
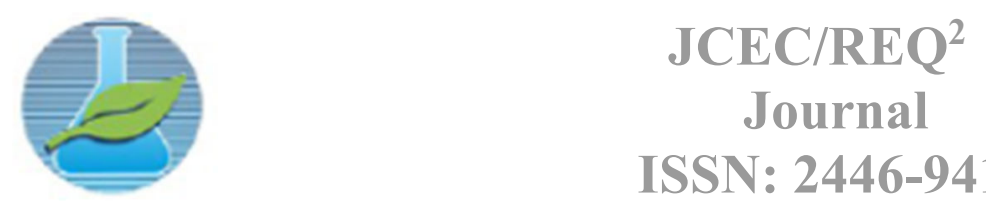

ISSN: 2446-9416

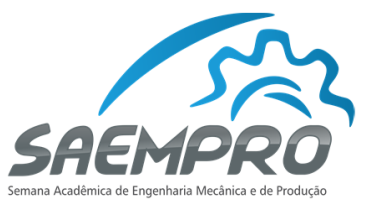

\author{
"EU, A INDÚSTRIA E O MUNDO" \\ 08 a 11 de novembro de 2016 no campus Viçosa da UFV \\ Departamento de Engenharia de Produção e Mecânica - DEP \\ Universidade Federal de Viçosa - UFV
}

\title{
ROTA DE FABRICAÇÃO DE UMA CHAVE MODELO YALE
}

\section{Gabriele Almeida de Paula, Gynakellen de Assis Santos, Letícia Assis Carmo, Lucas Benini}

Universidade Federal de Viçosa, Departamento de Engenharia de Produção e Mecânica

$\mathrm{Ph}$. Rolfs s/n - 36.570-900 - Viçosa - MG

gabriele.a.paula@gmail.com, lucas.benini@ufv.br

\section{INTRODUÇÃ̃O}

A utilização de chaves para os mais diversos propósitos faz parte do cotidiano de grande maioria da população mundial. Sejam destinadas à fechaduras, cadeados ou demais espécies de trancas, desde os modelos mais simples e comuns até os exemplares mais modernos como os codificados e presenciais, as chaves possuem a finalidade de fornecer segurança, privacidade e praticidade aos usuários.

O segredo da chave é formado pelo seu formato e pela dimensão dos dentes. Isso porque apenas uma chave com perfil equivalente e na posição correta poderá ser usada. Além disso, os dentes que formam uma base de apoio para pequenos pinos (sustentados por molas) ou tambores metálicos, colocados aos pares e alinhados no interior do cadeado ou fechadura. Quando a chave correspondente é inserida na fechadura, os pinos são alinhados aos dentes da chave de um modo que se permite girar o cilindro da fechadura, liberando a trava principal.

Um modelo de chave amplamente utilizado é o modelo Yale - Fig 1(a). Este modelo é indicado para portas externas, cadeados, gavetas e armários. A chave Yale possui apenas um segredo e é formada por um número de pinos que pode variar entre quatro e oito e se alinham aos dentes laterais, possibilitando, assim, a abertura. Uma variação da chave Yale é a chave Yale dupla, que possui dois segredos iguais, um em cada extremidade da chave, proporcionando mais segurança.

A chave Yale, assim como os demais tipos de chave, passa por diversos processos de fabricação desde o material em bruto até o produto final. Pode-se produzir uma chave utilizando diferentes rotas de fabricação, ou processos de fabricação, até de obter a chave com o segredo. $\mathrm{O}$ objetivo deste trabalho é a determinação de uma rota de fabricação para uma chave tipo Yale, considerando as características necessárias deste produto, processos produtivos e o processo de cópia da chave (chave com segredo).

\section{CARACTERÍSTICAS E FORMATO DO MATERIAL}

Por se tratar de um produto altamente disseminado e de utilização frequente, além de apresentar geometria singular (segredo) para os diferentes modelos fabricados, exige-se que o material para a confecção dos exemplares apresente boa resistência mecânica e alta maleabilidade, bem como seja fácil de fundir e de se trabalhar no geral, além de possuir durabilidade e resistência à corrosão adequadas. Os materiais mais utilizados na fabricação de chaves são o aço inoxidável, o alumínio, o latão e o zamac.

A comparação entre as propriedades mecânicas destes materiais permitiu concluir que o latão é o material mais indicado para a confecção do produto, uma vez que seu baixo ponto de fusão contribui na realização do processo de fundição, já que exige menos energia transferida na forma de 
calor para que passe do estado sólido para o líquido. Soma-se o fato do latão ser uma liga permite que as porcentagens dos seus diferentes componentes sejam manipuladas de forma a alcançar as propriedades desejadas. Dessa forma, ele é apresentado como um material maleável, dúctil e resistente ao impacto, características necessárias para a fabricação do produto em questão. Além disso, o preço de mercado do material é acessível, o que favorece uma boa relação custo-benefício.

\section{PROCESSOS PRODUTIVOS}

O processo de fabricação de uma chave inicia com uma barra de latão que é colocada em uma máquina de moldagem, que a divide em segmentos chamados lingotes e cada um deste irá se tornar uma chave. É necessário que esse material tenha propriedades como baixa tensão de escoamento e alta ductilidade. Os lingotes são inseridos em um aquecedor por indução, estes são aquecidos a $1000{ }^{\circ} \mathrm{C}$ e em seguida podem ser processados através dos processos de fundição ou forjamento.

Neste trabalho, a rota de fabricação da chave segue pelo processo de forjamento, uma vez que a fabricação de chaves não necessita de tolerâncias dimensionais estreitas e ser necessário uma alta produtividade. Além disso, o aquecimento do metal é necessário para facilitar a modelagem e diminuir o desgaste do equipamento utilizado e a possibilidade de fratura da peça.

Após a realização do processo de forjamento, a chave passa por um processo de lixamento que permite um melhor acabamento. A primeira etapa geralmente é manual, e o operador coloca a cabeça da chave em contato com uma lixa em rotação. Posteriormente ela é colocada em uma máquina-ferramenta de polir arestas que executa o polimento de ambos os lados da chave, deixando a chave livre das linhas de desbastes

Por fim, a chave é colocada em uma prensa hidráulica, de em média 75 toneladas, que a estampa com a marca e informações sobre a peça. Esse processo é relativamente e simples e é baseado na pressão que a prensa exerce sobre a peça causando uma deformação plástica. É necessário o correto dimensionamento da força aplicada sobre a chave para que não ocorram quebra e fratura, e/ou comprometa a estrutura da chave.

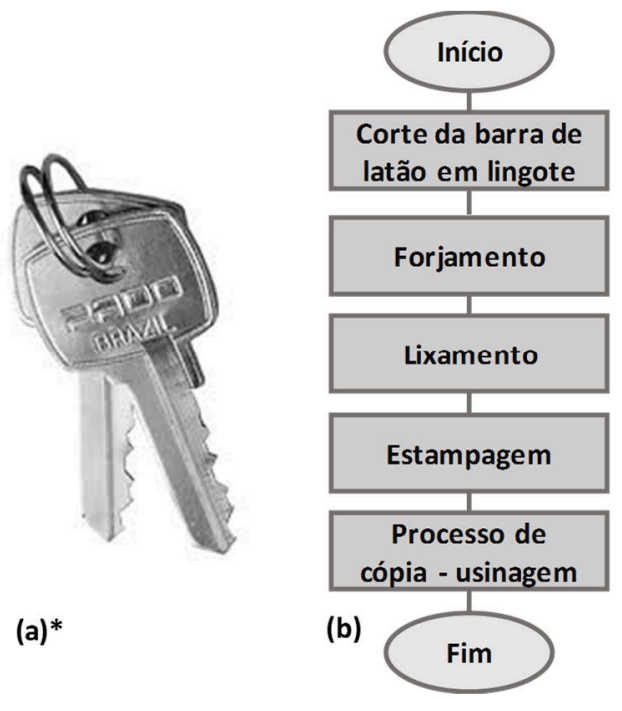

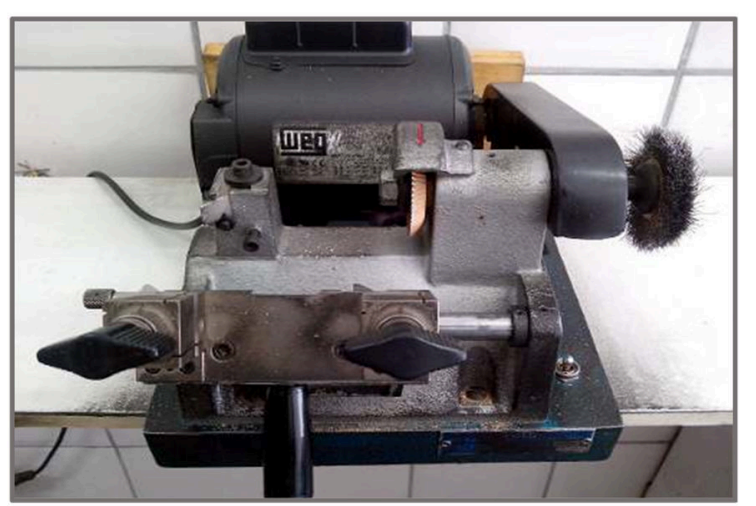

(c)*

Figura 1 - (a) Chave tipo Yale; (b) Rota de fabricação; (c) Máquina-ferramenta de cópia de chaves; *produto disponivel comercialmente.

A rota de fabricação acima descrita (Fig. 1(b)) trata da produção de chaves virgens, ou seja, chaves sem segredo. Optou-se por não abordar a rota de fabricação correspondente a chaves com segredo. As chaves virgens produzidas seguem para os demais processos fabricação para então serem comercializadas juntamente com a fechadura, ou ainda serem vendidas para clientes que efetuem a cópia de chaves. Para fazer a cópia de uma chave é necessário, além da chave virgem, 
uma chave modelo (a ser copiada) e uma máquina de cópia de chaves tipo Yale. Vale ressaltar que a chave virgem deve ter formato compatível com a chave modelo para que a cópia seja possível.

A máquina de chaves (Fig. 1(c)) - conta com um eixo metálico que serve de suporte para uma estrutura de encaixe das chaves. Essa estrutura pode se mover em relação ao eixo, no sentido horizontal e vertical. Para garantir que as chaves fiquem fixas durante esses movimentos elas são colocadas sobre um suporte metálico de espessura ajustável, de maneira que a chave fica presa pela pressão exercida por esse suporte. Além disso, a máquina também possui uma fresa e uma lixa rotativa.

O primeiro passo para efetuar a cópia de uma chave é colocar as chaves plana e modelo na máquina. As chaves devem ser posicionadas de forma que a chave modelo fique diante do pino metálico e a chave virgem fique diante da fresa. A partir do momento que as chaves estão posicionadas e fixadas de maneira adequada, liga-se a máquina e posiciona-se o suporte metálico de modo que a extremidade da chave modelo toque o pino. A máquina foi projetada de maneira que a distância entre o pino e a chave modelo permaneça sempre a mesma entre a fresa e a chave virgem.

O operador move o suporte das chaves no sentido horizontal do eixo, fazendo com que o pino percorra pelo contorno do segredo da chave modelo. Simultaneamente, cada ponto da chave virgem entra em contato com a fresa que efetua a usinagem copiando o segredo da chave modelo. Após o pino percorrer toda a chave modelo e a fresa usinar a chave virgem, completa-se o processo e a chave originada contém o mesmo segredo que a chave modelo. Por fim, coloca-se a chave copiada em contato com a lixa rotativa, com o intuito de dar um melhor acabamento à peça. Esse processo é chamado de lixamento.

O custo da copiadora de chaves varia de acordo com sua marca e modelo, mas é possível encontrar máquinas novas com um preço médio de $\mathrm{R} \$ 700,00$. Em longo prazo, tem também o gasto necessário para a troca da fresa, sendo que uma fresa nova para essa máquina custa por volta de R\$ 70,00, e pode produzir por volta de 8.000 chaves. É importante perceber que quanto maior o tempo de utilização da fresa, menor a precisão da cópia de chaves e, por este motivo, são maiores as chances de uma chave copiada não atender às necessidades de um cliente.

A produtividade da máquina vai depender da destreza do operador, uma vez que o processo não é automatizado. Estima-se que podem ser realizadas até 2 cópias por minuto, ou 120 cópias de chaves em uma hora de trabalho ininterrupto. Vale ressaltar que existem máquinas de cópia de chaves totalmente automatizadas, cuja precisão e volume de produção são muito maiores em relação ao processo manual. Por outro lado, são equipamentos bem mais caros, com uma faixa de preço médio de $\mathrm{R} \$ 17.000,00$.

\section{CONSIDERAÇÕES FINAIS}

Este trabalho abordou uma possível rota de fabricação de uma chave plana e o processo de cópia de chaves. Foi possível perceber a quantidade de processos de fabricação por trás de um produto relativamente simples e ao mesmo tempo a insuficiência de estudos e análises feitas neste contexto. Por esse motivo, muitas das informações apresentadas são oriundas do contato com pessoas envolvidas na produção e cópia de chaves. Além disso, é possível perceber a grande variedade de processos ou ferramentas possíveis para a fabricação de um mesmo produto. Por essa razão, os processos de fabricação de chaves podem ser diferentes para cada empresa, de maneira que cada uma deverá optar por aquele que conseguir atender suas necessidades pelo menor preço.

\section{REFERENCIA}

CHAVEIROSETC.BR. "Tipos de chave". Acesso em 20 Out. 2016. Disponível em $<\mathrm{http}: / /$ www.chaveiro.etc.br/dicas/tipos-de-chave $>$. 